\title{
Methodology to determine the parameters of historical earthquakes in China
}

\author{
Jian Wang ${ }^{1 *}$, Guoliang Lin ${ }^{2}$ and Zhe Zhang ${ }^{1}$
}

\begin{abstract}
China is one of the countries with the longest cultural tradition. Meanwhile, China has been suffering very heavy earthquake disasters; so, there are abundant earthquake recordings. In this paper, we try to sketch out historical earthquake sources and research achievements in China. We will introduce some basic information about the collections of historical earthquake sources, establishing intensity scale and the editions of historical earthquake catalogues. Spatial-temporal and magnitude distributions of historical earthquake are analyzed briefly. Besides traditional methods, we also illustrate a new approach to amend the parameters of historical earthquakes or even identify candidate zones for large historical or palaeo-earthquakes. In the new method, a relationship between instrumentally recorded small earthquakes and strong historical earthquakes is built up. Abundant historical earthquake sources and the achievements of historical earthquake research in China are of valuable cultural heritage in the world.
\end{abstract}

Keywords: Historical earthquake, Catalogue, Intensity, Historical archive, China

\section{Historical earthquake archives and field investigations}

China has a long culture tradition to record natural phenomena. Since Shang (Yin) Dynasty (16-11 century B.C.), there had been officers appointed by governors to record natural disasters including earthquakes. Under Qin Dynasty (221-206 B.C.), the united country started to emerge. The regime consisted of the central and local governments. Meanwhile, there had been a reform and a standardization of the literal system. These elements had been making more literal recordings possible. From Western Han (206 B.C.-24 A.D.), earthquakes had been recorded as "catastrophes" in official historical archives. In Song Dynasty (960 A.D.-1279 A.D.), print technique was utilized widely, which enabled writing and propagation more convenient. In Yuan Dynasty (1271-1368 A.D.), the four-rank pyramid regime was formed, which included the central government in the highest rank followed by province, canton, and county hierarchically. From that time, the annals and various recordings of

\footnotetext{
*Correspondence: wangjian@cea-igp.ac.cn

1 Institute of Geophysics, China Earthquake Administration, No 5. Minzu Daxue Nan Road, Haidian District, Beijing 100081, China

Full list of author information is available at the end of the article
}

different rank governments became popular. After the middle of Ming Dynasty (about 1475 A.D.), there were more villages with growing population. Meanwhile, the society was stable and the administration was effective. In such situation, the number of earthquake recordings had been increasing greatly and more details of disasters were described gradually.

\section{Two large-scale collections of historical earthquake archives}

In general, the historical earthquake recordings scatter in different documents. The historical documents concerning earthquakes were extracted and compiled as books, which are known as "historical earthquake archives". In the long history of China, there were several books to pick out the historical sources of earthquakes. The first such book "Tai Ping Yu Lan" appeared in 977 A.D. A total of 45 items of earthquakes between the eleventh century B.C. and 618 A.D. were compiled by Li Fang. In Yuan Dynasty, a total of 268 items of earthquakes were compiled in a book "Wen Xian Tong Kao" by Ma Duanlin. In 1725 A.D., 654 items of earthquakes were compiled in a book "Gu Jin Tu Shu Ji Cheng" (Li et al. 1960).

At the end of Qing Dynasty, a Chinese named Huang Bolu, who was a French churchman that time, collected 
historical earthquake sources of China. About 3322 items of historical sources from ancient time to 1895 A.D. were compiled in a book (two volumes), written in French. The first volume was published in 1909 and the second in 1913.

In 1950s, the collection of historical earthquake sources participated by seismologists was carried out first time. During that time, there were about two hundred engineering projects which needed assessment of seismic intensity in the sites. For this purpose, historians and seismologists were organized by Academia Sinica to collect historical earthquake sources systematically. With more than 2 years of hard work together, the historians and seismologists searched through more than 8 thousand kinds of historical literature. About 15,000 items of historical earthquake sources were discovered and picked out. After checking and analyzing, they compiled these historical earthquake sources chronologically. The results were compiled in a two-volume book: "Chronological Archives of Historical Earthquakes in China" (Historical earthquake working group of Seismological Committee of Academia Sinica 1956).

The second large-scale collection of historical earthquake sources occurred in the 1970s. Since 1977, historians and seismologists have been involved in this work, organized by the State Seismological Bureau (SSB; since 1998, SSB has been renamed as CEA-China Earthquake Administration), China Academy of Social Sciences, and Academia Sinica. Seismologist Xie Yu-shou and historian Cai Mei-biao were the editors in chief. This time they explored historical earthquake sources in a wider scope. Based on "Chronological archives of Historical Earthquake in China," large amount of supplement and emendation were made. Some earthquake documents were discovered and translated from Manwen (one of official literatures in Qing Dynasty) and Zangwen (literature of Zangzu, i.e., Tibet) archives. After 5-year hard work, a five-volume "Compilation of Historical archives of Chinese Earthquakes" was accomplished and published successively in 8 books during 1983-1987 (Xie and Cai 1983). Meanwhile, most provinces and autonomous regions published their own regional compilation of historical earthquake archives.

Besides the two large-scale collections of historical earthquake recordings, there are some collections done by individuals, but in small scale and generally in local regions. The work of compiling historical earthquake archives from historical sources has never been ceased in China.

\section{Field investigation}

Although most disaster descriptions of historical earthquakes came from the historical earthquake archives, we can also get information through field investigation in some special situations. For example, the relics of ancient builds damaged by historical earthquakes remained. From these relics, the intensity can be judged more correctly. If lucky enough, we can even get new discovered sources of historical earthquake. Such information may be obtained from unearthed stone stelae, notes kept by individuals, genealogy of a large family, or local orally spread legends. Because the two large-scale collections were mainly focused on historical sources at the levels of central and provincial government, there might be some sources undiscovered at town level.

To evaluate the intensity of historical earthquake more correctly and accurately, investigation on local topography, soil layers, hydrogeology, building material and craft is very necessary. These elements are very important in intensity evaluation, which can help us understand real historical circumstances better. So the investigation on the relics of historical earthquake is emphasized, and such works have be done continuously in China (Shi et al. 1992; Wang et al. 1998a, 2010; Wang 2004).

\section{Historical earthquake catalogues and spatial- temporal distribution}

In the 1950s, the "Chronological Archives of Historical Earthquakes in China" was compiled and almost at the same time the "Catalogue of Chinese Earthquake" was also edited. Since that time, Chinese seismologists have endeavored unceasingly to study and revise the catalogues to make them more systematical and perfect. There are many earthquake catalogues in China. Here we mainly introduce the four formal editions of the catalogues.

\section{Four formal editions of "The Catalogue of Chinese Earthquake"}

First edition of "The Catalogue of Chinese Earthquakes (CCE)" was published in 1960 ( $\mathrm{Li}$ et al. 1960). Li Shanbang (Li S.B., also S.P., Lee) was the editor in chief. This catalogue has two volumes. Volume one is the catalogue of earthquakes with magnitude greater than 4.7, covering the time period from 1189 B.C. to 1955 A.D. Totally 1180 earthquakes were listed, including 585 historical earthquakes. Here the "historical earthquake" means the earthquake without instrumental recordings, which parameters were determined only by intensity data. In China, the end year of "historical earthquakes" was determined to be 1911 A.D (Table 1). In the first edition, the parameters of 585 historical earthquakes were determined mainly according to the information in "Chronological Data of Historical Earthquakes in China." Volume two of this edition is the catalogue in each county. In China, there are more than two thousand counties totally. 
About one thousand and six hundred counties have historical earthquake archives. Most of them were concentrated in the Eastern China.

The second edition of "The Catalogue of Chinese earthquakes" was published in 1971 (Seismic Working Group of Central government 1971). The chief editor was still Li Shan-bang actually, although named "working group." This four-volume catalogue covered the time period from 1177 B.C. to 1969 A.D. The total number of earthquakes listed with magnitude greater than 4.7 is 2257, including 589 historical earthquakes (Table 1).

The third edition of "The Catalogue of Chinese earthquakes" was published in 1983 (Gu et al. 1983). Gu Gong-xu was the chief editor. Lin Ting-huang and Shi Zhen-liang were vice editors. This two-volume catalogue contains information on 3187 earthquakes, including 619 historical earthquakes, which covered the time period from 1831 B.C. to 1969 A.D (Table 1).

The fourth edition of "The Catalogue of Chinese earthquakes" includes two parts. Part one "The Catalogue of Chinese Historical Strong Earthquakes" was published in 1995 (Min et al. 1995). This historical earthquake catalogue covered the time period from the twenty third century B.C. to 1911 A.D., with a time span of more than 4100 years. It contains 1034 historical earthquakes with magnitude greater than 4.7. Min Zi-qun was the chief editor. Part two "The Catalogue of Chinese Present Earthquakes" was published in 1999, the earthquake parameters were determined by investigations and instrumental recordings (Wang et al. 1999). This catalogue covered the time period from 1912 to 1990 . A total of 4289 earthquakes were listed. Wang Su-yun, Wu Ge, and Shi Zhenliang were the editors in chief (Table 1).

In order to compile the Seismic Intensity Zoning Map of China (1990), the concise catalogue of Chinese earthquakes (CCCE) was published (informally) in 1988, which covered the time period from 78 B.C. to 1986 A.D.

\section{Table 1 Outline of the four editions of CCE}

\begin{tabular}{|c|c|c|c|c|c|}
\hline Edition & $\begin{array}{l}\text { Published } \\
\text { time }\end{array}$ & Chief editor & Time period & $N$ of $E$ & $\mathrm{~N}$ of $\mathrm{HE}$ \\
\hline $1 \mathrm{st}$ & 1960 & Li Shan-bang & $\begin{array}{l}1189 \\
\text { B.C.-1955 }\end{array}$ & 1180 & 585 \\
\hline $2 n d$ & 1973 & Li Shan-bang & $\begin{array}{l}1177 \\
\text { B.C.-1969 }\end{array}$ & 2257 & 589 \\
\hline $3 r d$ & 1983 & $\begin{array}{l}\text { Gu Gong-xu } \\
\text { et al. }\end{array}$ & $\begin{array}{l}1831 \\
\text { B.C.-1969 }\end{array}$ & 3187 & 619 \\
\hline 4th (I) & 1995 & $\begin{array}{l}\text { Min Zi-qun } \\
\text { et al. }\end{array}$ & $\begin{array}{l}2300 \\
\text { B.C.-1911 }\end{array}$ & & 1034 \\
\hline 4th (II) & 1999 & $\begin{array}{l}\text { Wang Su-yun } \\
\text { et al. }\end{array}$ & 1912-1990 & 4289 & \\
\hline
\end{tabular}

$N$ of $E$ number of earthquakes, $N$ of $H E$ number of historical earthquakes
Totally 5142 earthquakes with magnitude greater than 4.7 were listed. Min Zi-qun was the chief editor.

The four editions of CCE and a CCCE were all sponsored by the governments and recognized in whole country. There are some catalogues edited by individuals and local branches of State Seismological Bureau (SSB), which will not be introduced due to limited space.

\section{Atlas of isoseismals}

There are several atlases of isoseismals in China. Min $\mathrm{Zi}$-qun compiled an atlas of isoseismals including 64 earthquakes (Min 1957). As an important basic data for seismic intensity zoning, the atlas of Chinese Earthquake Isoseismals was published in 1979 (Compilation Group of China Seismic Intensity Zoning Map SSB 1979). A total of 151 items of earthquake isoseismals were delineated in this atlas, the time period of which covered from 1125 A.D. to 1976 A.D.

The more complete and detailed works were done by cooperation between seismologists from Institute of Geophysics S.S.B. and historians from Institute of Chinese Historical Geography, Fudan University. Three-volume "Atlas of the historical earthquakes in China" was the cooperative results of seismologists, historians, and geographers (Institute of geophysics 1986, 1990a, b).

\section{Spatial-temporal distribution of historical earthquakes}

With the catalogue of the fourth edition (Min et al. 1995), we will analyze the spatial-temporal distribution of historical earthquakes in China.

\section{Temporal distribution}

The temporal distribution of historical earthquake in China is shown in Fig. 1. We can notice that the temporal distribution is not balanced. Although the first earthquake recording appeared in 2300 B.C., there were only 7 earthquakes recorded before Western Han Dynasty (started since 206 B.C.; for details, see "Appendix"). The number of recorded earthquakes increases gradually. From Western Han Dynasty to the end of Song Dynasty (206 B.C. -1279 A.D., totally 1485 years), there were 98 earthquakes recorded. There were 35 earthquakes recorded in Yuan Dynasty (1271 A.D.-1368 A.D.), although which covered a relatively short time span. Between the end of Yuan and the early years of Ming Dynasty, there were a lot of wars and society was not stable. There was an obvious gap in the earthquakes recorded in the corresponding time period. Remarkable changes appeared in the middle of Ming Dynasty (Since 1475 A. D). Almost 70\% of recorded earthquakes occurred after that time. In the corresponding period, the society was stable and the administration was effective. 


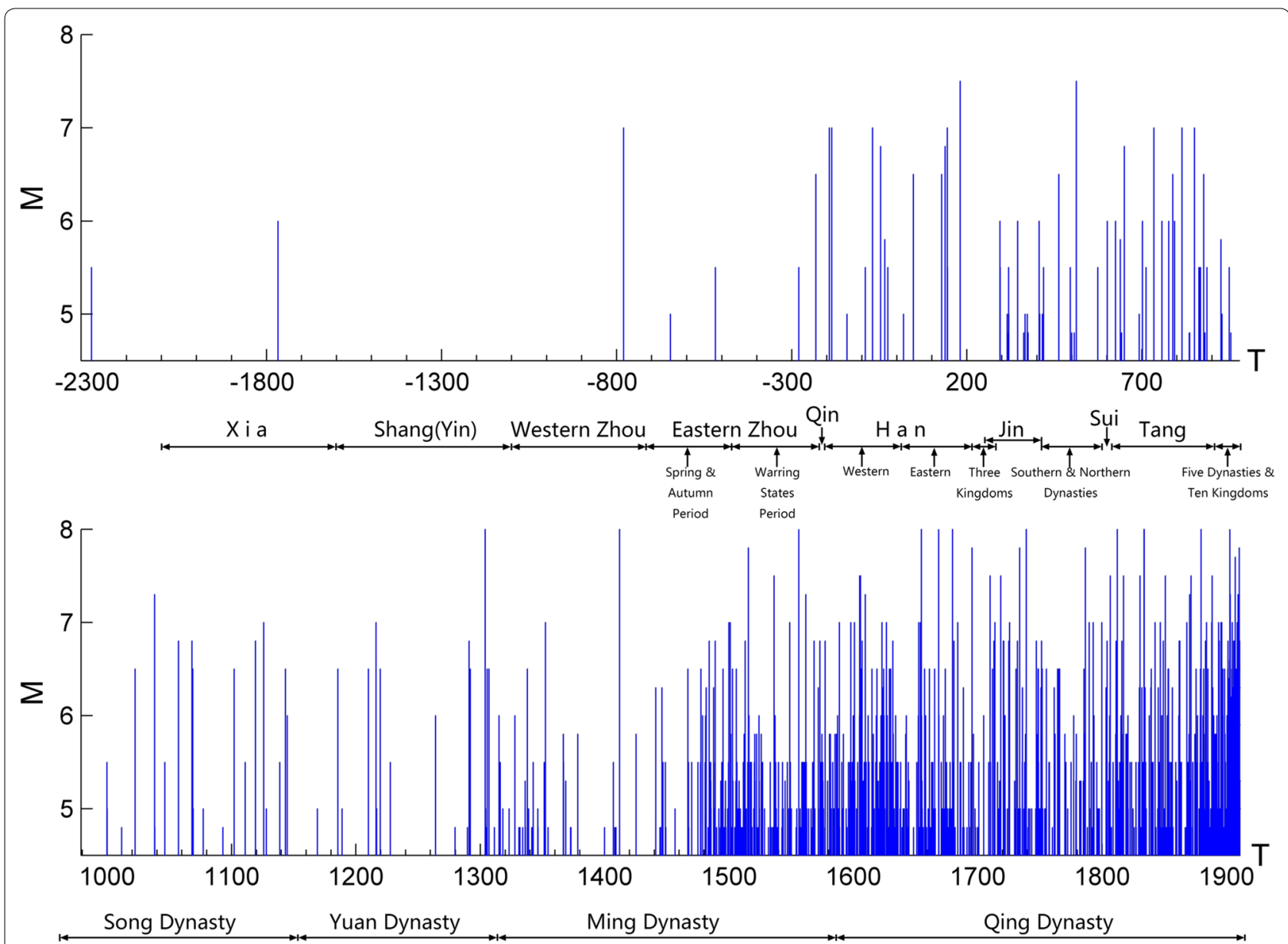

Fig. 1 Temporal distribution of historical earthquakes in China

So, the historical earthquake recordings can reflect the situation of the actual historical society to some extent from another aspect.

\section{Spatial distribution}

Spatial distribution is illustrated in Fig. 2, which is also not balanced. The most of recorded historical earthquakes were concentrated in the Eastern China.

Incremental frequency-magnitude distribution data are listed in Table 2. From Table 2, we can notice that the number of $M 4$ earthquakes is even less than that of $M 5$ earthquakes. It is obvious that the earthquakes below M5 are incomplete.

\section{Intensity scale and traditional methods}

The traditional methods to determine the parameters of historical earthquake rely heavily on the statistical relationship between intensity and the parameters. The relationship is a very important "bridge" in the traditional methods, which concerned the intensity scale. Firstly, we introduce the China intensity scale briefly.

\section{China intensity scale}

China intensity scale is a twelve-degree system. It was created by Li Shan-bang (Li 1954) and improved by Xie (1957). China Intensity Scale referred the intensity scales across the world, including the intensity scale of former Soviet Union in 1952 and Modified Mercalli Intensity Scale. In China Intensity Scale, seismic intensity was described according to four kinds of damage phenomena: house building; structure (including special ancient China buildings, such as memorial archway, pagoda, stele, rampart.); damage on the earth surface; and other phenomena. Glossary culled from historical records to describe the earthquake damage was subjoined to judge intensity from the historical documents easily (Li 1989). Chinese ancient words generally are different in font or meaning with nowadays. Such glossary would be helpful to those who are not familiar with ancient literature.

China Intensity Scale was supplemented and simplified by Liu (Liu 1978) according to new kinds of modern buildings destroyed by the recent years strong earthquakes both in China and across the world. China 


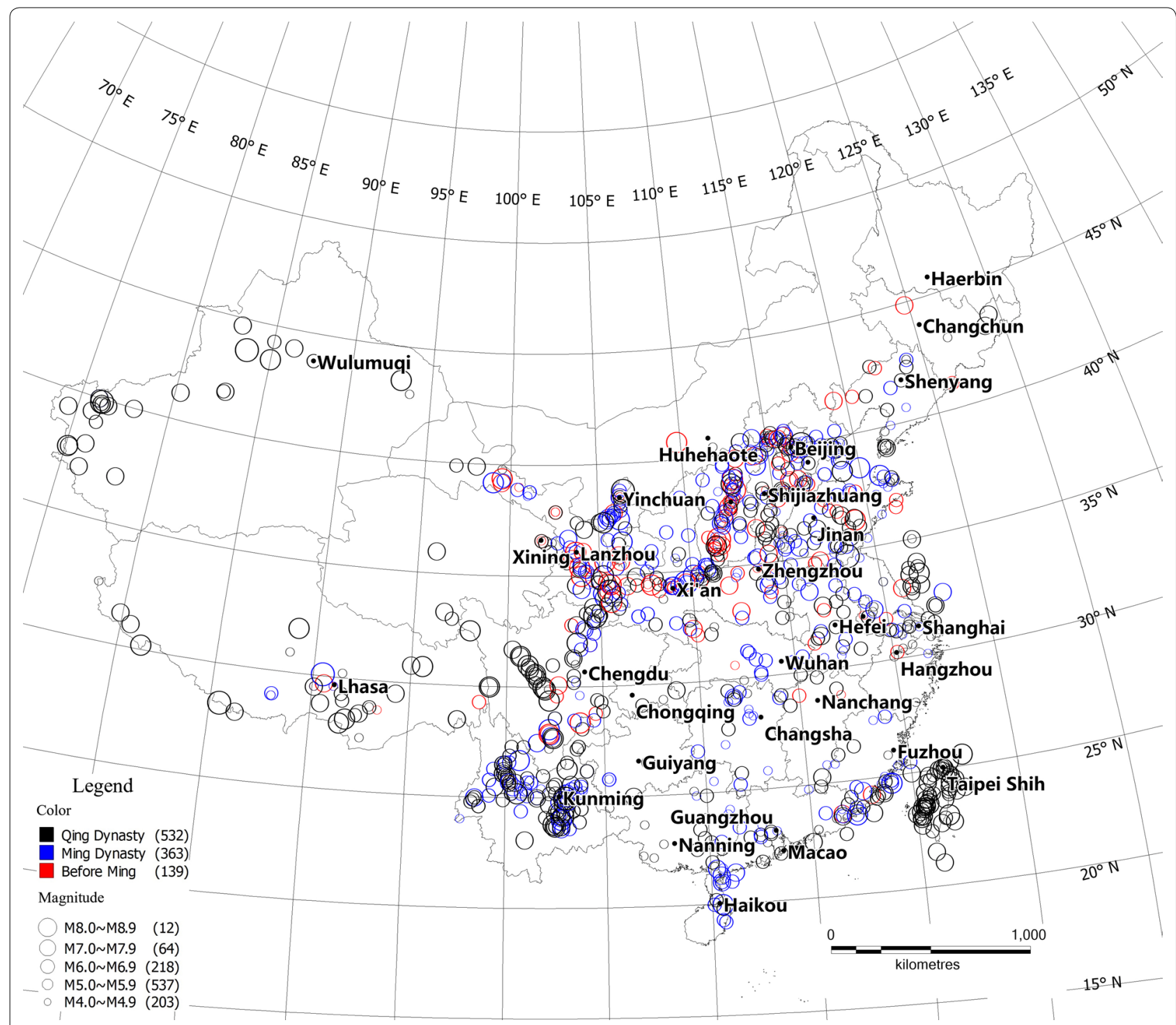

Fig. 2 Spatial distribution of historical earthquakes in China

Table 2 Incremental frequency-magnitude distribution (2300 B.C.-1911 A.D.)

\begin{tabular}{llllll}
\hline Magnitude range & $\mathbf{4 - 4 . 9}$ & $\mathbf{5 . 0 - 5 . 9}$ & $\mathbf{6 . 0 - 6 . 9}$ & $\mathbf{7 . 0 - 7 . 9}$ & $\mathbf{8 . 0 - 8 . 9}$ \\
\hline Number of events & 203 & 537 & 218 & 64 & 12 \\
Percentage of total (\%) & 19.63 & 51.93 & 21.08 & 6.19 & 1.16 \\
\hline
\end{tabular}

intensity scale was amended again in 1999 and became the National Standard then.

\section{The procedures of tradition methods}

Here we reconfirm the concept of "historical earthquake." In China, we define the "historical earthquake" as the earthquakes which parameters were only inferred from historical sources and not instrument recordings. Generally, the parameters of an earthquake include occurring time, epicenter, maximum intensity, and magnitude. If the data are enough, accuracy and focal depth may be inferred. The methods to determine the parameters of historical earthquakes include the following steps:

1. In a research region, historical recordings at all sites should be collected as completely as possible. The intensity of each site should be assessed according to the relevant destructive description.

2. Utilizing the events with instrumental parameters and intensities to work out the statistics or empirical 
relations between earthquake parameters and intensities. The relations will be extrapolated to infer the parameters of historical earthquakes.

3. In order to determine the magnitude of a historical earthquake, we should decide which statistical formula will be used according to the actual situation of intensity. For example, if a historical earthquake had enough recordings to draw out isoseismals, the earthquake magnitude can be inferred from the areas defined by the isoseismals (Wu 1989). The relation between magnitude and equivalent radius $(R)$ of each intensity region was listed as follows:

$$
\begin{aligned}
& \text { IV: } \quad M=2.16 \lg R+1.10 \\
& \text { V: } \quad M=2.06 \lg R+1.93 \\
& \text { VI: } \quad M=1.90 \lg R+3.06 \\
& \text { VII: } \quad M=1.85 \lg R+3.79
\end{aligned}
$$

The area of each isoseismal in different magnitude bin had been statistics based on more data (Wang et al. 1998b). The results enrich the relations between magnitude and intensity.

4. If a historical earthquake only has the peak intensity, its parameters can be estimated by the relation between the parameters and the peak intensity.

If the peak intensity $\left(I_{0}\right)$ is known, the formula (5) will be used to evaluate the magnitude of the historical earthquake $(M)$ :

$$
M=0.58 I_{0}+1.5
$$

The formula (5) was used in the edition 1st, 2nd, and 3rd of "The Catalogue of Chinese Earthquakes" (Li et al. 1960; Seismic Working Group of Central government 1971; Gu et al. 1983). In "The catalogue of Chinese historical strong earthquakes" (Min et al. 1995), the relations were different in each zone of whole China.

$$
\begin{aligned}
& \text { Eastern China: } M=0.579 I_{0}+1.403 \\
& \text { Western China: } \quad M=0.605 I_{0}+1.376 \\
& \text { Taiwan island: } \quad M=0.507 I_{0}+2.108
\end{aligned}
$$

5. If a historical earthquake recorded in a region with no damaging, only felt intensity data however, In this case, the relation between magnitude and radius of felt area $(D)$ can be used:

$$
M=2.21 \lg D+0.63
$$

Generally, the intensity of felt area may be intensity III or IV (Wu 1989).

6. The center of isoseismal or the equivalent center of several intensity sites might be taken as the epicenter generally. In some cases, the peak intensity site should be regarded as the epicenter.

No doubt, a suitable relation should be selected to evaluate the magnitude of a historical earthquake according to actual intensity data.

\section{A new approach}

Anyway, the traditional methods have limitations, because they rely heavily on the historical earthquake archives. As we all know, there are many reasons that the historical earthquake archives might be incomplete. If a historical earthquake occurred in a place no persons living that time, there might be no disaster recorded at all. No doubt, a lot of historical earthquakes are missed which could not be sought by traditional methods.

In recent years, we tried a new approach to judge historical earthquake depending on modern instrumental data. In China, since 1960s, local earthquake observation networks have been built. With the accumulation of such small earthquake data, a very interesting phenomenon was discovered. There are many small earthquakes that occurred around the epicenters of strong historical earthquakes (Wang 1985). In order to analyze the phenomenon quantitatively, we suggested a method to deal with seismic pattern quantitatively and named it "calculation of seismic density" (Wang 1999, 2001).

\section{Definition and calculation of the seismic density}

Firstly, we introduce a metric known as the "seismic density" that quantifies the degree of clustering of the epicenter distribution. In a research region, we delineate a grid with interval $\Delta$ in longitude and latitude. For each grid node, we specify an outer circle centered on the node of maximum radius $R$. For the $j$ th node, only those earthquakes with epicenters inside the circle will contribute to the index of seismic density. The index is then a mixture of physical and geometric measures of clustering of location, number, and magnitude (ratio to the size of the earthquake's fracture). For pragmatic reasons, we use metrics that are logarithmic (such as the magnitude), mainly to reduce the potential for large statistical sampling error that might occur using linear measures (such as energy or moment release). For consistency, we also use a logarithmic measure of the separation distance $r_{i j}$. For the $j$ th node at time $t$, the seismic density index is then defined by 


$$
I_{j, t}=\sum_{i=1}^{n} \frac{\mathrm{M}_{\mathrm{i}}}{\Delta m \ln \left(r_{\mathrm{ij}}\right)}, \quad R_{\min } \leq r_{\mathrm{ij}} \leq R
$$

where $\mathrm{M}_{\mathrm{i}}$ is the magnitude of $i$ th earthquake. $\Delta m$ is the difference between the threshold magnitude for complete reporting and the maximum magnitude, introduced as a rough normalization factor. The finite minimum distance $R_{\text {min }}$ avoids problems with the singularity in $1 /\left(\ln r_{\mathrm{ij}}\right)$ at $r_{\mathrm{ij}}=0$. Once the calculation has been applied to every node, we can construct contours of the density index. The main ideas and steps are illustrated in Fig. 3.

\section{The example in Beijing, China}

We choose Beijing as an example to demonstrate the new method. Beijing is the capital of China, a metropolis which includes several administrational districts. The total area of Beijing is about $16,800 \mathrm{~km}^{2}$. Our research region is chosen as a quadrangle to cover the main part of administrational districts $\left(115.5-117.5^{\circ} \mathrm{E}, 39.5-41.0^{\circ} \mathrm{N}\right)$. The earliest observation network has been established around Beijing since 1966, providing the best instrumentally recorded catalogue in China (Institute of Geophysics, CEA 2006). There are 926 earthquakes with $M_{\mathrm{L}} \geq 2$ recorded from 1970 to 2014, which are estimated as a complete catalogue. There are 8 strong historical earthquakes $(M \geq 6)$, which parameters determined by extensive historical archives (in Fig. 4).

The grid size $\Delta$, search radius $R$, and resolution $R_{\min }$ are determined by the accuracy of epicenter location. In our research region, the first-level accuracy is not larger than $5 \mathrm{~km}$; so, we take the grid size $\Delta$ as 0.05 degree of longitude and latitude, roughly equal to $5 \mathrm{~km}$. The $R_{\min }$ represents the ultimate resolution of epicenter location. In China, the minimum distance that can be resolved by the networks is about 2 3 km (Institute of Geophysics, CEA 2006); therefore, we take $R_{\min }=\mathrm{e}(\mathrm{e} \approx 2.71828)$ as a mathematically convenient number within this range. The maximum radius $R$ should also depend on the grid size $\Delta$ and not contain too much overlapping data. Similarly it should be greater than or equal to $(\Delta / \sqrt{2})$, so that events are not restricted to within the dimension of the elementary grid cell. Here we take $R=10 \mathrm{~km}$, i.e., including all the data from the nearest and next-nearest neighbor nodes. The $\Delta m=\left(M_{\max }-M_{\min }\right)$ is 3.0, given $M_{\min }=2.0$ and $M_{\max }=5.0$. The resulting contours of seismic density and the epicenter distribution for the magnitude thresholds $M_{\min }=2.0$ are drawn in Fig. 4. We must point out that the metric is relative, which may be sensitive to the choice of parameters. Nevertheless the main characteristics of cluster identified remain robust (Wang 2001).

The highest seismic density is 50 . The seismic density contours in Fig. 4 map out clear anomalies associated with the characteristics of the population of earthquake magnitudes and locations. Some strong historical earthquakes fall into seismic density zones, such as the M6 earthquake in 294 and M63/4 earthquake in 1484. One anomaly has two subsidiary structures, one seismic density center to the SE (near Sanhe) and another side lobe to the NE (near Huangsongyu). The epicenter of great M8 earthquake in 1679 is just located in the center near Sanhe. For the event in 1679, there were enough historical archives to draw out the isoseismals. The contour at intensity X and XI has a similar shape and orientation as those of seismic density (Fig. 5). Such elongated contours in the density anomaly are likely to be associated with the orientation of the causative rupture plane inferred from the major axis of the isoseismals. This complexity could also be due to a second smaller event that is not recorded, or to a major sub-event within the $M 8$ earthquake, as seen for example in the $M s 8$ Wenchuan earthquake in 2008 (Zhang et al. 2008, 2010).

\section{Region under Calculation of density investigation at $j$ th node}
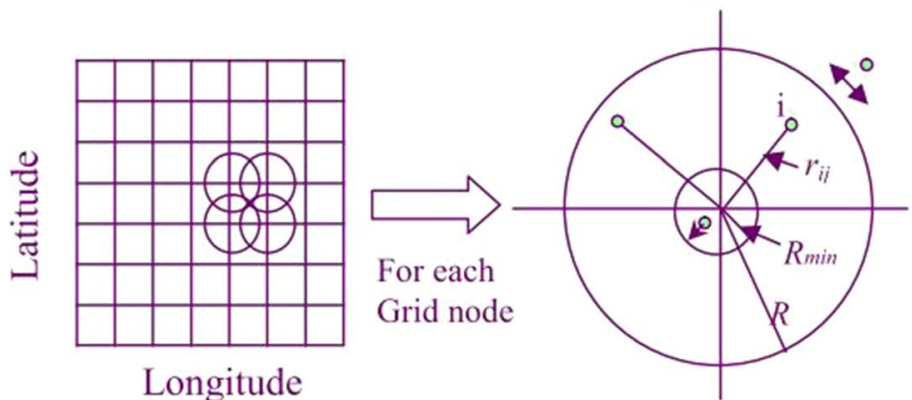

\section{Seismic density} contours

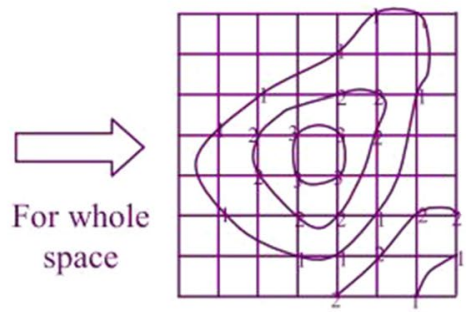

Fig. 3 A sketch map illustrating the seismic density index calculation. The circles on the left-hand side of the diagram represent the outer annulus of the middle diagram 


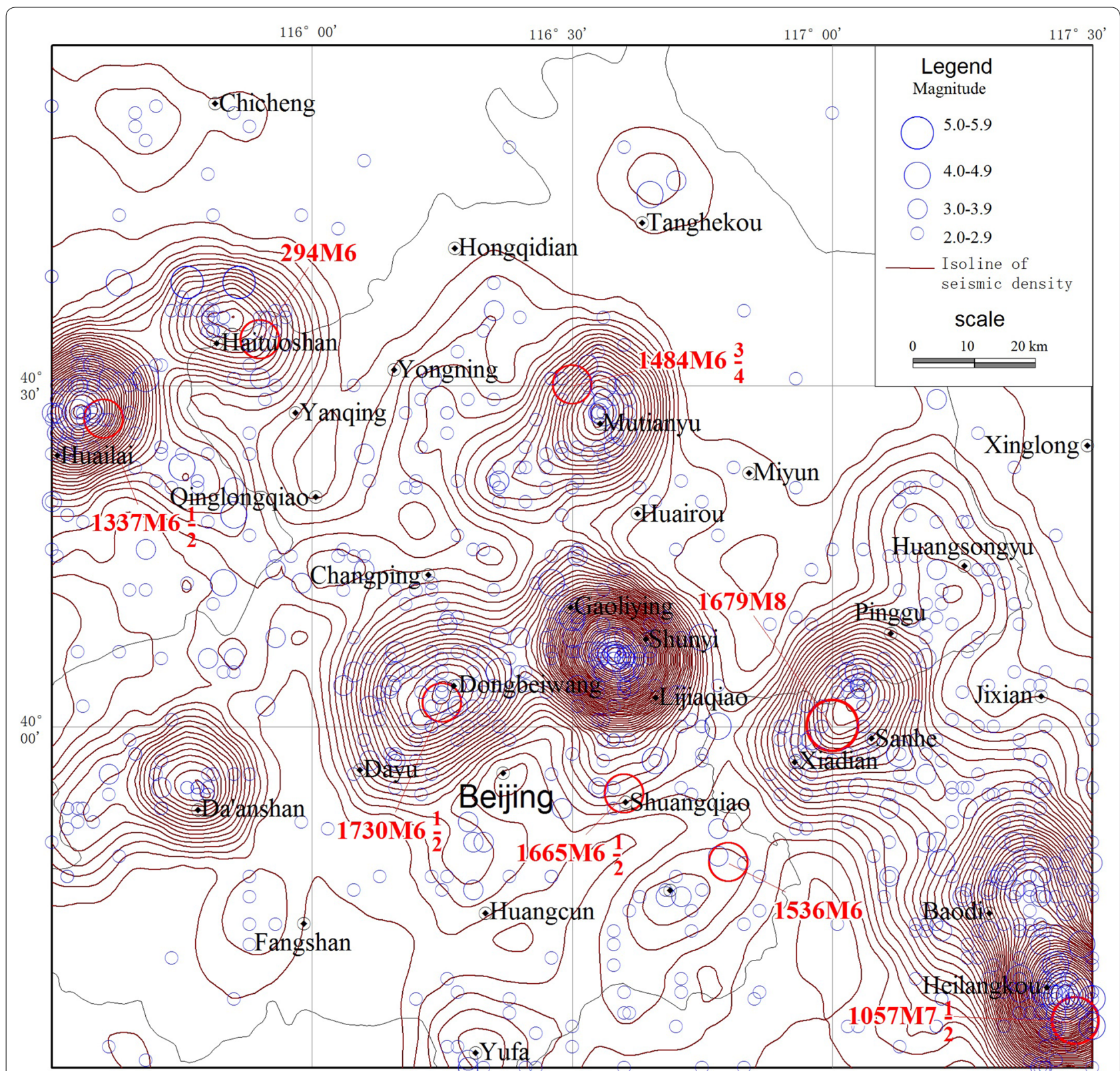

Fig. 4 Plot of the Epicenters of events of different magnitude (blue circles) and the contour of the seismic density index defined in Eq. 10. The values of contours start from $j_{j, t}=1$ and increase in unit steps

Within each seismic density zone, the temporal distribution of earthquakes is analyzed quantitatively. According to the statistics, a regularity has been discovered that the temporal distribution of the seismic density zone varies with time very smoothly, which coincides with the epicenters of strong historical earthquakes. We can utilize this regularity to improve the strong historical earthquake locations with large error originally, and even find a new candidate zone of a missed strong historical earthquake (Wang et al. 2004a, 2010; Wang 2007, 2011).

\section{Geophysics implication and application prospect}

The modern-day seismicity can point out the locations of persistent weaknesses in the lithosphere. Such persistent but relatively stationary clustering is also observed in the other regions of the world such as in the New Madrid of the eastern US (Page and Hough 2014) and in Austria (Wang et al. 2008). This persistence has also been observed on a much smaller scale in the location of acoustic emissions (AE) during cyclic loading in laboratory rock deformation tests. Once a zone of weakness 


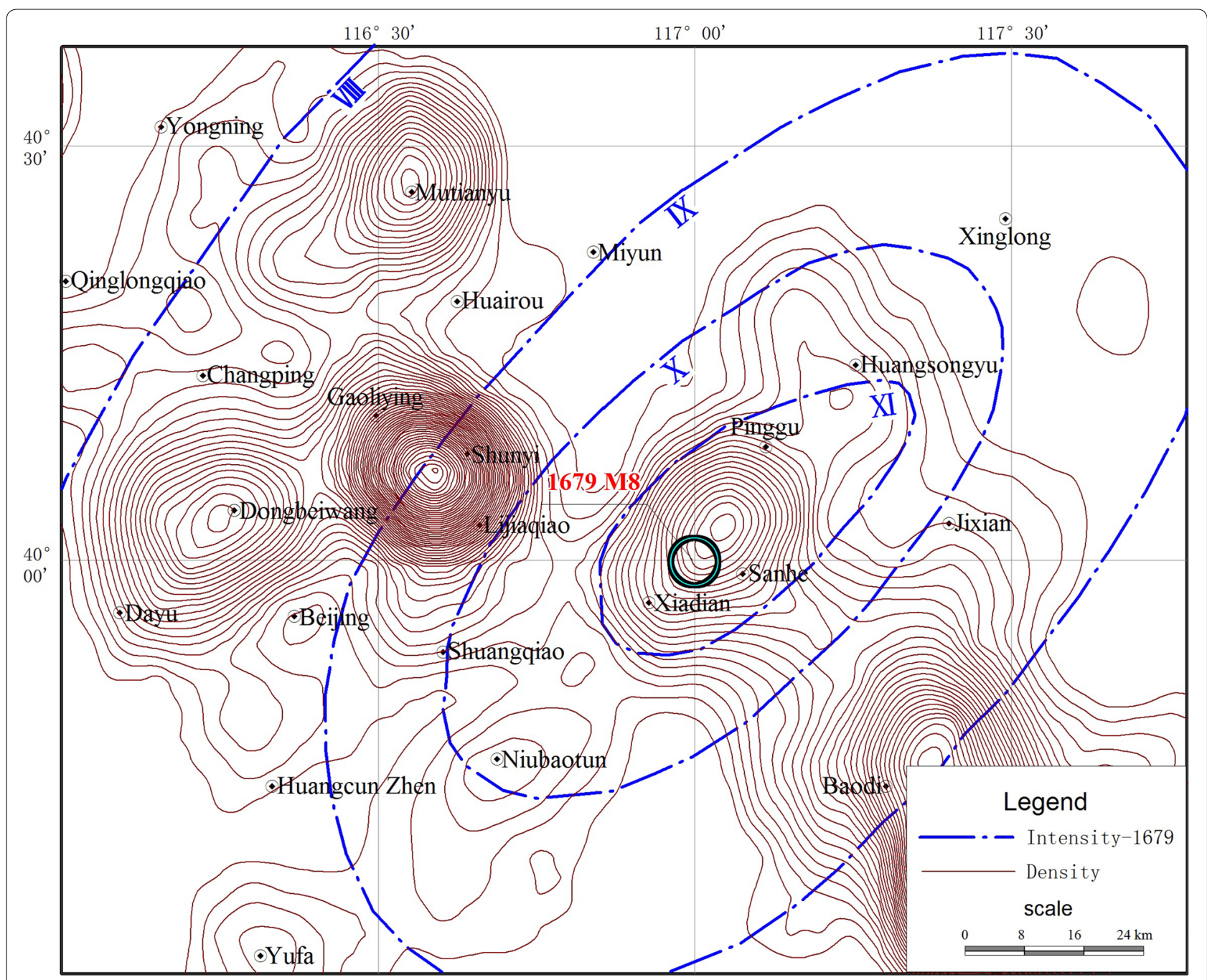

Fig. 5 Comparison of seismic density with the isoseismals of the historical earthquakes M8 in 1679

is created, subsequent loading in the next cycle appears to produce more $\mathrm{AE}$ events from the same volume (Sondergeld and Estey 1981). From the view of fracture mechanics, the occurrence of a strong earthquake means that the local crust medium has been experiencing a process from integrity to fragmentation. This process can be not backtracked usually.

We must point out that this method would only work as a method of identifying candidate zones for large historical or palaeo-earthquakes in cases where there is modern-day seismicity. However, this is not always the case. Many faults known to be active from palaeo-seismic observations in zones of shallow intra-plate continental deformation are not associated with current seismically active zones. This highlights the importance of combining studies of ours with alternate methods such as paleoseismic and geodetic methods, as well as expanding the historical search for significant past earthquakes. Anyway, under some suitable circumstance, this method might help us to judge historical earthquake parameters and amend them, even find a new candidate site.

Combining historical earthquake and instrumental data, we can get the information of local crustal medium and inherent relationship between them. The results let us know more about the complex of seismicity, and meanwhile, we understand better about the geophysics behind them.

\section{Retrospect and prospect}

Since 1950s, huge numbers of investigation and research have been done on historical earthquakes for several generations in China. The resplendent accomplishments have been achieved. The investigations and researches can been concluded in the following aspects: 
1. Comprehensive collection of historical earthquake archives;

2. Besides the textual archives, field investigations and excavations have been done on many important historical earthquake sites. Large evidences were found on ancient buildings, steles, and pagodas, and even tombs.

3. China seismic intensity scale has been established and improved.

4. Utilizing the earthquakes with both instrumental parameters and intensity data to get the statistics or empirical relations between them.

5. Compilations of historical earthquake catalogues and isoseismal atlases.

6. Probe a new approach to amend the parameters of strong historical earthquakes, which does not depend on the historical sources.

7. Application: historical earthquake data prolong the time and extend the space, which enable seismicity analysis more reasonably. The results are applied in long mid-term earthquake prediction, seismic hazard analysis, and seismic intensity zoning (Wang et al. 2004b).

Although a lot of work and research have been carried out, more efforts are still needed. Here, we just list out some possible further works:

1. Supplement collection of scattering historical sources. After two large-scale collections, there are still historical earthquake documents that remain undiscovered. Because these documents are scattered, they are more difficult to collect.

2. Detailed field investigations and excavations on historical earthquake sites.

This kind of work is especially needed in the Western China, where population and historical documents are sparse. With less man-made demolishment and dry nature circumstance, the vestige of historical earthquakes might keep a longer time generally. Cooperation between seismologists and archaeologists on historical earthquakes research will bring more achievements.

3. It is important to reconstruct actual circumstance of a historical earthquake, such as considering building anti-earthquake ability in historical time period, effects of local hydrology, geology, topography, and physiognomy. This will help us comprehend the historical disaster documents synthetically.
4. Actual situation of historical sources is very complex. For example, some documents of a historical earthquake disaster were not original recordings, which might be already summarized. Generally, after a long time and undergoing number of wars, the original recordings had been missed. Because such summarized documents are easier to keep, they may have more chance to be retained till to nowadays. Common situation is that the disaster recordings were summarized at a county, but the actual peak intensity recordings at several villages might be missed. Unscrambling such summarized recordings depends on experience and knowledge of old experts to a large extent. There is an urgent task to make clear how the experts got their results, because some of experts have died and many experts are older than 70 years.

5. Seismic intensity data at sites derived from original disaster recordings are very valuable. We try our best to collect and unscramble historical sources to rebuild intensity data at sites. Seismic intensity database of electronic version should be built, which are more convenient to use intensity data to evaluate the parameters of historical earthquakes with quantitative methods (Lin and Wang 2012).

6. The seismic density method has been applied in some parts of the Eastern China. In the next step, we will expand it to the whole China and amend the Catalogue of Chinese Historical Earthquakes again. We are pursuing the wide international cooperation to test the seismic density method in different regions of the world. The final purpose should be to find out the general regularity behind complex seismicity (Wang et al. 2008).

Abundant historical earthquake archives and plentiful achievements of historical earthquake research in China are of valuable cultural heritage. We will continue to translate and introduce them in order for more experts to realize and utilize the treasure. It seems no possible to introduce Chinese historical earthquakes in all aspects in a paper. We just tried our best to outline the main points. There might be some omissions and misunderstandings.

Abbreviations

SSB: State Seismological Bureau (1973-1997); CEA: China Earthquake Administration (1998 to now); CCE: Catalogue of Chinese Earthquakes; CCCE: Concise Catalogue of Chinese Earthquakes.

\section{Authors' contributions}

JW has made substantial contribution to conception and design, acquisition of data, and analysis and interpretation of data; GL has done some work concerned with collection of data and calculations, and took part in discussion; ZZ has done some work concerned with statistical analysis and drawing figures, and took part in discussion. All authors read and approved the final manuscript. 


\section{Author details}

${ }^{1}$ Institute of Geophysics, China Earthquake Administration, No 5. Minzu Daxue Nan Road, Haidian District, Beijing 100081, China. ${ }^{2}$ Yunnan Seismological Bureau, China Earthquake Administration, Kunming, China.

\section{Acknowledgements}

The partial work of this paper is supported by the NSFC of China and NERC/ ESRC Newton of UK fund cooperation programme on Increasing Resilience to Natural Hazards in Earthquake-prone regions in China. We thank the two anonymous peers for their fair comments and helpful suggestions.

\section{Competing interests}

The authors declare that they have no competing interests.

\section{Funding}

The partial work of this paper is supported by the NSFC of China with the project title: Probability and Uncertainty in Risk Estimation and Communication (PUREC-41661134014).

\section{Appendix: Table of Chinese Dynasties}

\section{Xia (21-16 century B.C.)}

Shang (Yin) (16-11 century B.C.)

Western Zhou (11 century-771 B.C.)

Eastern Zhou (770-221 B.C.)

Spring and Autumn Period (770-475 B.C.)

Warring States Period (475-221 B.C.)

Qin (221-207 B.C.)

Western Han (206 B.C.-24 A.D.)

Eastern Han (24-220 A.D.)

Three Kingdoms (220-280)

Western Jin (265-316)

Eastern Jin (317-420)

Southern and Northern Dynasties (420-589)

Sui Dynasty (581-618)

Tang Dynasty (618-907)

Five Dynasties and Ten Kingdoms (907-979)

Song Dynasty (960-1279)

Yuan Dynasty (1271-1368)

Ming Dynasty (1368-1644)

Qing Dynasty (1644-1911)

The Republic of China (1911-1949)

The People's Republic of China (founded in 1949)

Received: 7 September 2016 Accepted: 16 February 2017 Published online: 27 February 2017

\section{References}

Compilation Group of China Seismic Intensity Zoning Map SSB (1979) Atlas of chinese earthquake isoseismals, 1-107. Seismic Publish House, Beijing (in Chinese)

Gu GX, Lin TH, Shi ZhL, Li Q, Wu HY et al (1983) The catalogue of chinese earthquakes (1831 B.C.-1969 A.D.), 1-663. Science and Technology Publish House, Beijing (in Chinese)

Historical earthquake working group of Seismological Committee of Academia Sinica (1956) Chronological archives of historical earthquakes in China (two volumes), 1-1653. Science Publishing House, Beijing (in Chinese)
Institute of Geophysics, CEA (2006) Earthquake monitoring chorography, 1-19. Seismological Publish House, Beijing (in Chinese)

Institute of geophysics, State Seismological Bureau \& Institute of Chinese Historical Geography, Fudan University (1986) Atlas of the historical earthquakes in China (The Ming Dynasty), 1-194. China Cartographic Publishing House, Beijing (in Chinese)

Institute of geophysics, State Seismological Bureau \& Institute of Chinese Historical Geography, Fudan University (1990a) Atlas of the historical earthquakes in China (The period from remote antiquity to the Yuan Dynasty), 1-174. China Cartographic Publishing House, Beijing (in Chinese)

Institute of geophysics, State Seismological Bureau \& Institute of Chinese Historical Geography, Fudan University (1990b) Atlas of the historical earthquakes in China (The Qing Dynasty period), 1-244. China Cartographic Publishing House, Beijing (in Chinese)

Li SB (1954) On the application of seismic scales. Acta Geophysica Sinica 3(1):35-54 (in Chinese with English abstract)

Li Q (1989) Assessments on China historical earthquake intensity, Special collection on China historical earthquake research (1), 1-4. Seismological Publish House, Beijing (in Chinese)

Li SB, Wu HY, Guo ZJ, Mei SR, Min ZQ (1960) The catalogue of Chinese earthquakes, 1-399. Science and Technology Publish House, Beijing (in Chinese)

Lin GL, Wang J (2012) Compilation of Chinese historical earthquake data by building up a database system based on seismic intensity points. Acta Seismologica Sinia 34(1):118-124 (in Chinese with English abstract)

Liu HX (1978) On the concept and application of earthquake intensity. Acta Geophysica Sinica 21(4):340-351 (in Chinese with English abstract)

Min ZQ (1957) Study of strong earthquakes from historical records. Acta Geophysica Sinica 6(1):49-58 (in Chinese with English abstract)

Min ZQ, Wu G, Jiang ZX, Liu CS, Yang YL et al (1995) The catalogue of Chinese historical strong earthquakes (B.C. 23-A.D. 1911), 3-471. Seismological Publish House, Beijing (in Chinese)

Page MT, Hough SE (2014) The new madrid seismic zone: not dead yet. Science 343(6172):762-764 doi:10.1126/science.1248215

Seismic Working Group of Central government (1971) The catalogue of Chinese earthquakes, 1-327. Science and Technology Publish House, Beijing (in Chinese)

Shi ZL, Li Q, Cheng YF (1992) Investigation on the relic of China historical earthquakes (466 B.C.-1900 A.D.). Seismological Publishing House, Beijing (in Chinese)

Sondergeld CH, Estey LH (1981) Acoustic emission study of microfracturing during the cyclic loading of westerly granite. J Geophys Res 86(B4):2915-2924

Wang ZG (1985) The "long-term" activity of large earthquake areas. Acta Seismologica Sinia 7(3):254-266 (in Chinese with English abstract)

Wang J (1999) Research on characteristics and application of seismic magnitude-number constitution, Ph.D. dissertation of Institute of Geophysics, China Seismological Bureau: Beijing (in Chinese with English abstract)

Wang J (2001) Seismic pattern treatment method through calculation of seismic density at grid nodes. Acta Seismologica Sinia 14(3):274-279

Wang J (2004) Historical earthquake investigation and research in China. Ann Geophys 47(2/3):831-838

Wang J (2007) Historical earthquakes and a tsunami in Bohai Sea. Acta Seismologica Sinia 20(5):584-592

Wang J (2011) Seismic density and strong historical earthquakes in the region including Beijng, Tianjin and Tangshan. 1-160. Seismic Publish House, Beijng (in Chinese)

Wang J, Hammerl CH (2008) Seismic density and its relationship with midstrong historical earthquakes in Austria. 503-510. 31st General Assembly of the European Seismological Commission ESC 2008, Hersonissos, Crete, Greece, 7-12 Sept 2008

Wang J, Zhang XD, Yu SJ, Yang YL (1998a) Statistical research on the strong earthquake risk ranges in Chinese mainland. Earthq Res China 14(3):2631 (in Chinese with English abstract)

Wang J, Yang YL, Zhang XD, Cai KM (1998b) Textual research and investigation on two doubtful historical earthquake in Jiaodong peninsula, Shandong province. Earthq Res China 14(3):43-50 (in Chinese with English abstract)

Wang SY, Wu G, Shi ZL et al (1999) The catalogue of recent earthquakes in China (A.D. 1912-A.D. 1990), 1-511. China Science and Technology Publish House, Beijing (in Chinese) 
Wang J, Wang SY, Xu GY, Yang YL, Wu X (2004a) Investigation and parameter emendation on the earthquake in Weihai, Shandong Province in 1948. Earthq Res China 20(4):419-424 (in Chinese with English abstract) Wang J, Zhang XD, Wu X, Wang SY (2004b) Seismic characteristics near the epicenter of Hongtong, Shanxi, $M=8$ earthquake in 1303 and its implication. Acta Seismologica Sinia 17(4):274-279

Wang J, Wu X, Gao AJ, Chen K, Shao L (2010) Probing an approach to amend the parameters of historical earthquakes: an example of the A.D. 294 Yanqing earthquake in Beijing. Acta Seismologica Sinia 32(1):108-117 (in Chinese with English abstract)

Wu HY (1989) The evaluation of historical earthquake magnitude. Special collection on China historical earthquake research (1), 97-104. Seismological Publish House, Beijing (in Chinese)

Xie YS (1957) A new scale of seismic intensity adapted to the conditions in Chinese territories. Acta Geophysica Sinica. 6(1):35-48 (in Chinese with English abstract)
Xie YS, Cai MB, Wang HA, Wen LM (1983) Compilation of historical archives of Chinese Earthquakes (Vol. 1), 1-227. Science Publish House, Beijing (in Chinese)

Zhang Y, Fen WP, Xu L, Zhou H, Chen YT (2008) Tempo-spatial rupture process of Wenchuan earthquake in 2008. Science in China (Series D. Earth SCi 38(10):1186-1194 (in Chinese with English abstract)

Zhang Y, Xu L, Chen YT (2010) Fast inversion of rupture process for 14 April 2010 Yushu, Qinghai, earthquake. Acta Seismol Sin 32(3):361-365 (in Chinese with English abstract)

\section{Submit your manuscript to a SpringerOpen ${ }^{\circ}$ journal and benefit from:}

- Convenient online submission

- Rigorous peer review

- Immediate publication on acceptance

- Open access: articles freely available online

- High visibility within the field

- Retaining the copyright to your article 